\title{
ARTICLE OPEN \\ Proof of mechanism and target engagement of glutamatergic drugs for the treatment of schizophrenia: RCTs of pomaglumetad and TS-134 on ketamine-induced psychotic symptoms and pharmacoBOLD in healthy volunteers
}

Joshua T. Kantrowitz ${ }^{1,2,3}$, Jack Grinband ${ }^{1,2}$, Donald C. Goff ${ }^{3,4}$, Adrienne C. Lahti ${ }^{5}$, Stephen R. Marder (D) $^{6}$, Lawrence S. Kegeles ${ }^{1,2}$, Ragy R. Girgis ${ }^{1,2}$, Tarek Sobeih ${ }^{3}$, Melanie M. Wall ${ }^{1,2}$, Tse-Hwei Choo ${ }^{1,2}$, Michael F. Green ${ }^{6}$, Yvonne S. Yang ${ }^{6}$, Junghee Lee (ID ${ }^{6}$, Guillermo Horga ${ }^{1,2}$, John H. Krystal ${ }^{7}$, William Z. Potter ${ }^{8}$, Daniel C. Javitt ${ }^{1,2,3}$ and Jeffrey A. Lieberman ${ }^{1,2}$

Glutamate neurotransmission is a prioritized target for antipsychotic drug development. Two metabotropic glutamate receptor $2 / 3$ (mGluR2/3) agonists (pomaglumetad [POMA] and TS-134) were assessed in two Phase lb proof of mechanism studies of comparable designs and using identical clinical assessments and pharmacoBOLD methodology. POMA was examined in a randomized controlled trial under double-blind conditions for 10-days at doses of 80 or $320 \mathrm{mg} / \mathrm{d}$ POMA versus placebo (1:1:1 ratio). The TS-134 trial was a randomized, single-blind, 6-day study of 20 or $60 \mathrm{mg} / \mathrm{d}$ TS-134 versus placebo (5:5:2 ratio). Primary outcomes were ketamine-induced changes in pharmacoBOLD in the dorsal anterior cingulate cortex (dACC) and symptoms reflected on the Brief Psychiatric Rating Scale (BPRS). Both trials were conducted contemporaneously. 95 healthy volunteers were randomized to POMA and 63 to TS-134. High-dose POMA significantly reduced ketamine-induced BPRS total symptoms within and between-groups ( $p<0.01, d=-0.41 ; p=0.04, d=-0.44$, respectively), but neither POMA dose significantly suppressed ketamineinduced dACC pharmacoBOLD. In contrast, low-dose TS-134 led to moderate to large within and between group reductions in both BPRS positive symptoms $(p=0.02, d=-0.36 ; p=0.008, d=-0.82$, respectively) and dACC pharmacoBOLD $(p=0.004, d=-0.56$; $p=0.079, d=-0.50$, respectively) using pooled across-study placebo data. High-dose POMA exerted significant effects on clinical symptoms, but not on target engagement, suggesting a higher dose may yet be needed, while the low dose of TS-134 showed evidence of symptom reduction and target engagement. These results support further investigation of $\mathrm{mGluR2/3}$ and other glutamate-targeted treatments for schizophrenia.

Neuropsychopharmacology (2020) 45:1842-1850; https://doi.org/10.1038/s41386-020-0706-z

\section{INTRODUCTION}

All current FDA-approved drug treatments for schizophrenia act by antagonizing dopamine at the $D_{2}$ receptors. While they often reduce psychotic symptoms and prevent their recurrence [1, 2], they have significant limitations in their efficacy and cause extensive side effects [3-6].

Efforts to develop drugs acting at novel molecular targets have been largely unsuccessful. Among the candidate biologic targets for treatment development, glutamate $[7,8]$ is one of the highest priorities. However, studies of glutamate-targeted drugs have not successfully led to FDA-approved treatments [9-11].

This begs the question of whether in prior studies the glutamate target itself failed, or the compounds tested failed to sufficiently engage the target. A target engagement study assesses whether the experimental agent is present in the brain and binding its molecular target in adequate concentrations to exert its therapeutic effects. While PET remains the gold-standard technology by which to measure target engagement [12], there are very few radioligands that have been developed for glutamate receptors. Other biomarkers, such as EEG or fMRI, are informative, but provide less direct, functional measures of target engagement.

We previously reported the results of biomarker validation studies using ketamine-induced changes in resting BOLD fMRI response (termed pharmacoBOLD) and ${ }^{1} \mathrm{H}-\mathrm{MRS}$ glutamate+glutamine peak for their utility as biomarkers for subsequent target engagement studies [13]. Ketamine is a non-competitive antagonist at $\mathrm{N}$-methyl-D-aspartate glutamate receptors (NMDAR). In animal models, ketamine administration induces an acute increase in glutamate release and recycling - sometimes termed the glutamate "surge" - that is thought to reflect an attempt of the glutamate system to achieve neurotransmission in the face of NMDAR inhibition [14-16].

Glutamate reuptake in glia accounts for $\sim 50 \%$ of energy expenditure in the brain [17], so that changes in glutamate/ glutamine cycling and energy expenditure are highly correlated [18-21]. The increased energy expenditure, in turn, leads to an

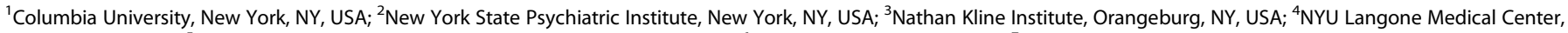

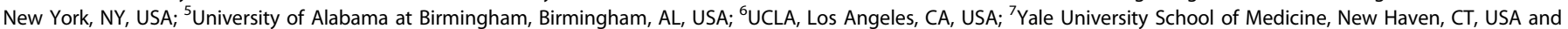
${ }^{8}$ National Institutes of Health, Bethesda, MD, USA

Correspondence: Jeffrey A. Lieberman (Jeffrey.Lieberman@nyspi.columbia.edu)

Received: 14 February 2020 Revised: 12 April 2020 Accepted: 6 May 2020

Published online: 13 May 2020 
increase in local cerebral blood flow that can be detected using BOLD imaging [22-24]. As a result, pharmacoBOLD can be used as a putative biomarker of glutamate response $[13,25]$ and a measure of functional target engagement. The effects of NMDAR antagonist-induced glutamate release have been measured in rodents by microdialysis $[26,27]$, pharmacoBOLD $[22,28]$, and locomotor hyperactivity $[29,30]$ and shown to be suppressed by presynaptic metabotropic glutamate type $2 / 3$ receptor (mGluR2/3) agonists. These results should predict antipsychotic efficacy; however, they have not been replicated in humans [26, 27].

While both pharmacoBOLD fMRI and ${ }^{1} \mathrm{H}$-MRS were sensitive measures in our previous study [13], pharmacoBOLD was the most robust measure, with a between group effect size of 5.4 vs. placebo. Therefore, for the currently reported project, we used ketamine pharmacoBOLD $\mathrm{fMRI}$ to evaluate the effects of two experimental mGluR2/3 agonist prodrugs, pomaglumetad (POMA/ LY2140023) and TS-134, on ketamine effects in healthy controls. In contrast to previous single-dose pharmacoBOLD studies [31], we assessed sustained exposure of these medications, more closely replicating the intended (chronic) clinical utilization.

The POMA study was funded by the National Institute of Mental Health Fast-Fail Trial for Psychotic Spectrum disorders (FAST-PS) project. We hypothesized that the reason for POMA's failure in pivotal Phase III trials [32-34] was due to insufficient dosing and that higher doses were warranted to engage the target [31]. We compared the most efficacious POMA dose used in pivotal studies $(80 \mathrm{mg})$ with a dose $4 \mathrm{x}$ as high $(320 \mathrm{mg})$ in a multi-center study powered to detect a between group, large effect size difference (Cohen's $d \geq 0.80 \mathrm{sd}$ ). In contrast, the TS-134 study was supported by Taisho Pharmaceutical R\&D Inc, and was a single-center, singleblind study using an asymmetric randomization, powered to detect within-group effects and to estimate effect-sizes to assist in the design of follow-up clinical trials.

As the studies were conducted contemporaneously using similar but not identical designs, we present the results of these two mGluR2/3 agonist studies in parallel. In particular, identical pharmacoBOLD methodology was used. The main differences were 10 days (for POMA) versus six days (TS-134) of treatment duration of dosing of experimental medication and subject monitoring (outpatient, multi-center treatment for POMA and inpatient, single-center treatment for TS-134).

\section{METHODS AND MATERIALS}

Subjects

Written informed consent was obtained from all participants, as approved by the participating Institutional Review Boards. Both trials were conducted under CONSORT guidelines between April 2017 and April 2019. (See Supplement for full study protocols and Clinicaltrials.gov: NCT02919774, NCT03141658).

Volunteers were aged 18 to 55 years old without current or past Axis I or II psychiatric or substance history (SCID DSM V) [35]; a first-degree relative with schizophrenia; a history of adverse reaction to an NMDAR modulator, violence, suicidality or significant medical illness, including hypertension $(>140 / 90)$ or significant head injury; or current psychotropics.

\section{POMA study design}

This was a randomized, placebo-controlled, double-blind, multisite, outpatient investigation conducted at CUMC/NYSPI, UAB, UCLA and NYULMC. Subjects were randomized in a 1:1:1 ratio to ten days of bid low-dose $(80 \mathrm{mg} /$ day), high-dose $(320 \mathrm{mg} /$ day), or placebo, with the first and last doses taken in clinic. Active POMA (LY404039) and prodrug (LY2140023) levels were assessed on day 1 (one-hour post dose), day 5 (random) and pre/post day 10 pharmacoBOLD scan. The planned sample size was 81 completers,

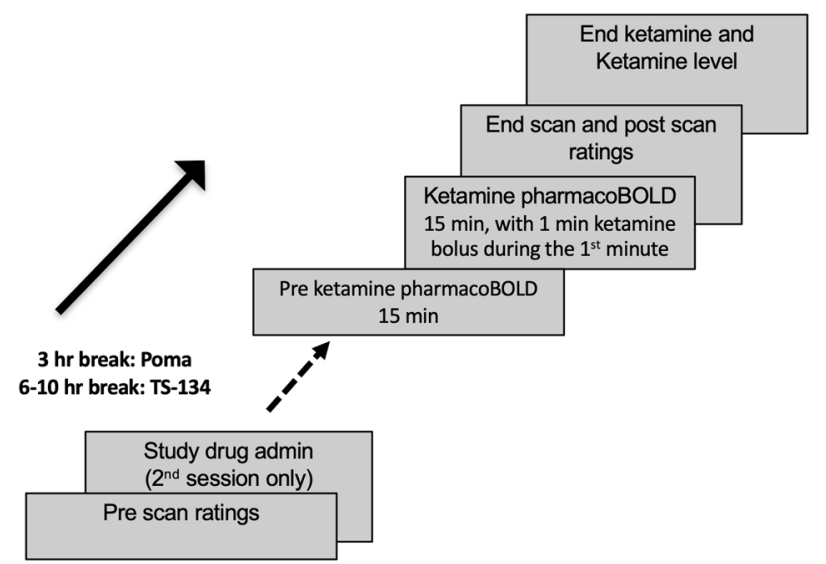

Fig. 1 Model of pharmacoBOLD sessions: Both the POMA and TS134 studies followed the same procedures during pharmacoBOLD sessions.

powered from Mehta et al. [31]. A randomization list was produced by the study biostatistician, using blocks of three, with stratification by site.

\section{TS-134 study design}

This was a randomized, placebo-controlled, single-blind, singlesite (CUMC/NYSPI) inpatient investigation. Study investigators/ statistical/imaging analysis were operationally blinded. Subjects were randomized in a 5:5:2 ratio to six days of QD low-dose (20 $\mathrm{mg})$, high-dose $(60 \mathrm{mg})$ or placebo. TS-134 levels were assessed on day $6,3 \mathrm{~h}$ post dose. The planned sample size was 60 completers with valid, analyzable MRI scans, and was powered to detect within-group effects for effect-size estimation for the design of follow-up clinical trials. A randomization list was produced by the study biostatistician.

PharmacoBOLD methods

Two $15 \mathrm{~min} \mathrm{~T}^{*}$-weighted echoplanar imaging scans were collected before and after a $0.23-\mathrm{mg} / \mathrm{kg}, 1-\mathrm{min}$ bolus of racemic ketamine hydrochloride (Ketalar; Parke Davis, Morris Plains, NJ; Fig. 1). The ketamine bolus was administered without subsequent infusion, and was identical to the bolus used in our biomarker development study [13] (see Emethods). Subjects were monitored frequently for blood pressure and continuously with EKG and pulse-oximetry by a study physician and assessed for the clearance of ketamine effects prior to discharge. A subset of subjects in both studies $(n=61)$ underwent additional monitoring using a pulse oximeter and respiration belt.

To qualify for randomization, subjects were required to show a within session increase of $\geq 0.5 \%$ from pre-ketamine baseline to peak ketamine response in the dorsal anterior cingulate cortex (dACC) during the screening pharmacoBOLD. The second pharmacoBOLD scan was conducted $\sim 3 \mathrm{~h}$ after the last dose for POMA and 8 (6-10) h after the last dose of TS-134, consistent with cerebrospinal fluid $T_{\max }$ of the two agents.

The Brief Psychiatric Rating Scale (BPRS) [36] was used to assess for ketamine-induced psychosis and Clinician Administered Dissociative States Scale (CADSS) [8] was used to assess for ketamine-induced non-specific disassociation. Both scales were completed twice per session: prior to and immediately following measurement of ketamine levels, $20 \mathrm{~min}$ after the ketamine bolus and $\sim 5 \mathrm{~min}$ after each MRI ended. BPRS subscales were defined as previously [8], including the 4-item BPRS positive symptoms: conceptual disorganization, hallucinatory behavior, suspiciousness, and unusual thought content. 
1844
Regions of interest

Based on our prior work showing that ketamine-induced pharmacoBOLD activity was largest in the dACC [13], our predefined primary ROI was the dACC. Additional voxelwise, whole brain analysis was conducted, along with secondary ROls per a recently published study using POMA [31], including a prespecified secondary anterior insula ROI for the TS-134 study only.

Statistical analysis

Demographics, screening pharmacoBOLD, and clinical responses were summarized by randomized treatment group and differences tested using ANOVA and $x^{2}$ tests.

The study drug effect on the primary target engagement outcome (pharmacoBOLD response) was tested using linear regression models, calculated as the \%difference in peak postketamine pharmacoBOLD response at the final session compared to screening, modeled for each treatment group. Mean withingroup and pairwise contrasts for group differences were estimated and tested for significance.

As it was adequately powered, the POMA study is presented independently with primary between-group analysis. Due to the asymmetric randomization and small number of participants who received placebo, models were fit both within study and between study for the TS-134 study, using a post-hoc, pooled across studies CUMC/NYSPI placebo group to increase the $n$ and statistical power. This approach was permitted by the identical pharmacoBOLD design across studies and a comparable between study placebo group change for the BPRS total $(d=-0.13)$ and dACC pharmacoBOLD $(d=0.04)$.

POMA models were adjusted for site. Similar models were used to assess treatment effects on clinical measurements, including the primary psychosis measure (BPRS total and subscales), the CADSS and in a post hoc subsample, controlling for heart rate in pharmacoBOLD analysis.

Spearman correlation coefficients were used to examine the association between pharmacoBOLD and symptomatic response change, and blood levels of ketamine and study drug. Analyses were carried out using SAS 9.4. Cohen's $d$ effect sizes, expressed in SD units, were calculated, with suppression of ketamine effects (improvements) noted by negative $d$ values. The significance level was defined as $p<0.05$, and moderate and large effect sizes defined as $d \geq 0.4$ and $d \geq 0.8$, respectively. Voxelwise analysis was not corrected for multiple comparisons.

\section{RESULTS}

Ascertainment and description of sample (consort charts: Supplemental Figs. 1 and 2)

$P O M A$. Ninety-five subjects were randomized in the POMA study, with 81 subjects completing both MRI scans. In total, 76 subjects were included in the efficacy analysis, including 27 at high-dose, 21 at low-dose, and 28 at placebo. Subjects were dropped from the efficacy analysis due to poor imaging quality $(n=5)$ or noncompletion ( $n=14$, including 6 subjects who withdrew consent, 4 adverse events, 2 lost to follow up, and 2 MRI malfunction). Only two non-completers were withdrawn by study investigators, both for non-serious adverse events unrelated to study treatment: concussion $(n=1)$ and sinus tachycardia with atrial fibrillation secondary to vomiting on day $1(n=1)$.

TS-134. Sixty-three subjects were randomized in the TS-134 study, with 61 subjects completing both MRI scans. In total, 59 subjects were included in the efficacy analysis, including 25 at high-dose, 24 at low-dose, and 10 at placebo. Subjects were dropped from the efficacy analysis due to poor imaging quality $(n=2)$ or noncompletion ( $n=2$; both subjects with adverse events unrelated to study treatment). 
POMA
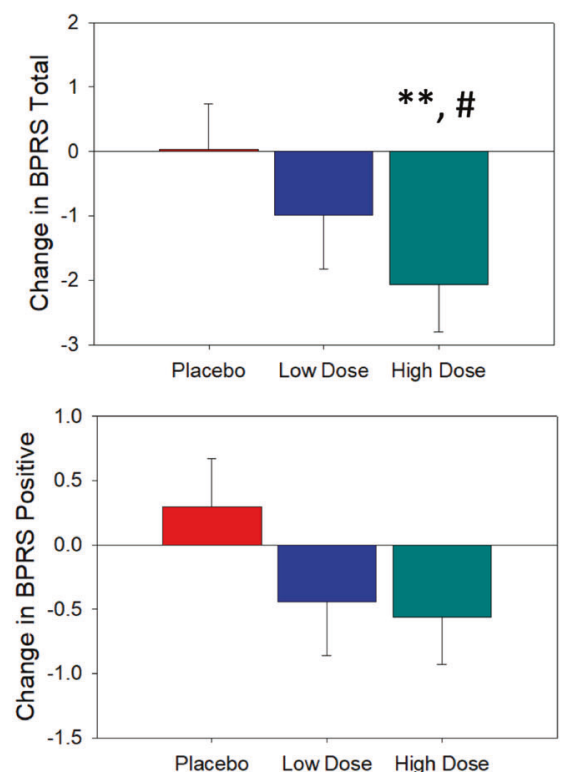

TS-134
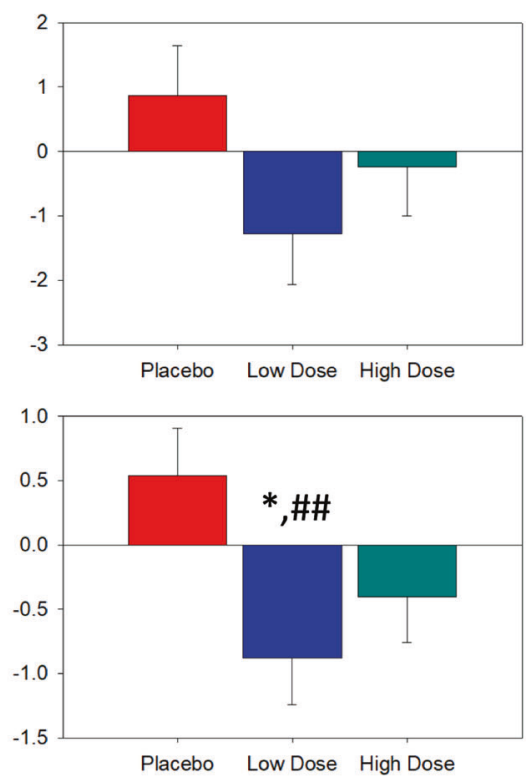

Fig. 2 Bar graph of changes following ketamine administration on final assessments as compared to screening in BPRS total (top row) and BPRS positive (bottom) for the POMA and TS-134 study. TS-134 results are for the combined Columbia University Medical Center/New York State Psychiatric Institute (CUMC/NYSPI) placebo sample. Model estimated mean \pm standard error. ${ }^{*}=<0.05$ and ${ }^{* *}=<0.01$ for within group changes; $\#=<0.05$ and $\#=<0.01$ for between group changes vs. placebo.

There were no significant within study treatment group differences at screening for either study (Table 1 , all $p>0.22$ ).

Effects on symptoms (Supplemental Tables 1 and 2)

As expected [13], psychotic and dissociative symptoms reflected by the BPRS and CADSS ratings of subjects in all treatment groups were increased by ketamine at both screening and final sessions. The differences between the screening-final responses between treatment groups was interpreted as a measure of the POMA and TS-134 effects on ketamine stimulated glutamate neurotransmission.

POMA. High-dose POMA significantly reduced BPRS total scores ( $t_{69}=2.1, p=0.04, d=-0.44$, Fig. 2, top left), along with trendlevel, moderate to large effect size reductions in BPRS positive ( $t_{69}=1.6, p=0.10, d=-0.41$, Fig. 2, bottom left) and BPRS negative $\left(t_{69}=1.9, p=0.067, d=-0.83\right)$ symptoms compared to placebo. Low-dose POMA total and BPRS positive effects were not significant, but a significant reduction vs. placebo was seen for BPRS negative $\left(t_{69}=2.2, p=0.02, d=-1.06\right)$.

TS-134. Low-dose TS-134 treatment significantly reduced BPRS positive symptoms $\left(t_{56}=2.5, p=0.02, d=-0.36\right)$, along with trend-level reductions in BPRS total $\left(t_{56}=1.9, p=0.06, d=-0.32\right)$ within-groups. Because of the asymmetric randomization resulting in a small $n$ in the placebo group of the TS-134 study, we combined subjects who received placebo from both studies to increase the $n$ and statistical power in a post hoc analysis. The between placebo groups (POMA vs. TS-134) effect size was small for the BPRS $(d=-0.13)$, suggesting that they were comparable, supporting the pooled placebo group analysis.

Using this pooled placebo group, we found trend-level, moderate effect size between-group differences in BPRS total symptoms ( $t_{69}=1.9, p=0.057, d=-0.48$, Fig. 2 , top right) and significant, large effect size changes in BPRS positive symptoms $\left(t_{69}=2.7, p=0.008, d=-0.82\right.$, Fig. 2 , bottom right) for low-dose TS-134 compared to placebo. The BPRS positive symptoms change was largest in the Hallucinatory Behavior $(d=-0.69)$ and Unusual Thought Content items $(d=-0.79)$. High-dose TS134 had no significant within or between-group effects.

CADSS: there were no significant medication effects on nonspecific disassociation symptoms (CADSS) for any group in either study. Within group effects were larger in the POMA than in the TS-134 study (Supplemental Tables 1 and 2).

Effects on MRI-pharmacoBOLD in dACC (Supplemental Tables 1 and 2)

As previously demonstrated [13], ketamine increased BOLD activity across nearly all gray matter areas except primary visual and orbitofrontal cortex (Fig. 3, top right) at screening. In all, $84.2 \%$ of 216 subjects from both studies who received a screening ketamine infusion met criteria for being a pharmacoBOLD responder to ketamine (within session increase of $\geq 0.5 \%$ in the dACC).

POMA: Neither low-dose nor high-dose POMA had significant effects on the primary outcome measure of target engagement, dACC pharmacoBOLD response (Fig. 3, top left).

TS-134: In contrast, low-dose TS-134 produced a significant, within-group, reduction on dACC pharmacoBOLD of $30.7 \%\left(t_{56}=\right.$ 2.98, $p=0.004, d=-0.56$ ), and a nonsignificant, moderate effect size between-group, within study difference vs. placebo $\left(t_{56}=\right.$ $-1.6, p=0.12, d=-0.57)$.

The between placebo groups (POMA vs. TS-134) effect size was small for the dACC pharmacoBOLD $(d=0.04)$, supporting the pooled placebo group analysis. Using the pooled placebo group, trend-level differences of moderate effect size were seen $\left(t_{70}=\right.$ $1.8, p=0.079, d=-0.50$, Fig. 3, bottom left) for low-dose TS-134. High-dose TS-134 had no significant within or between-group effects on dACC pharmacoBOLD.

\section{Correlational analyses}

There were no significant correlations between symptoms and pharmacoBOLD responses in either study, nor any significant age, site or gender effects for the main outcomes of either study. 

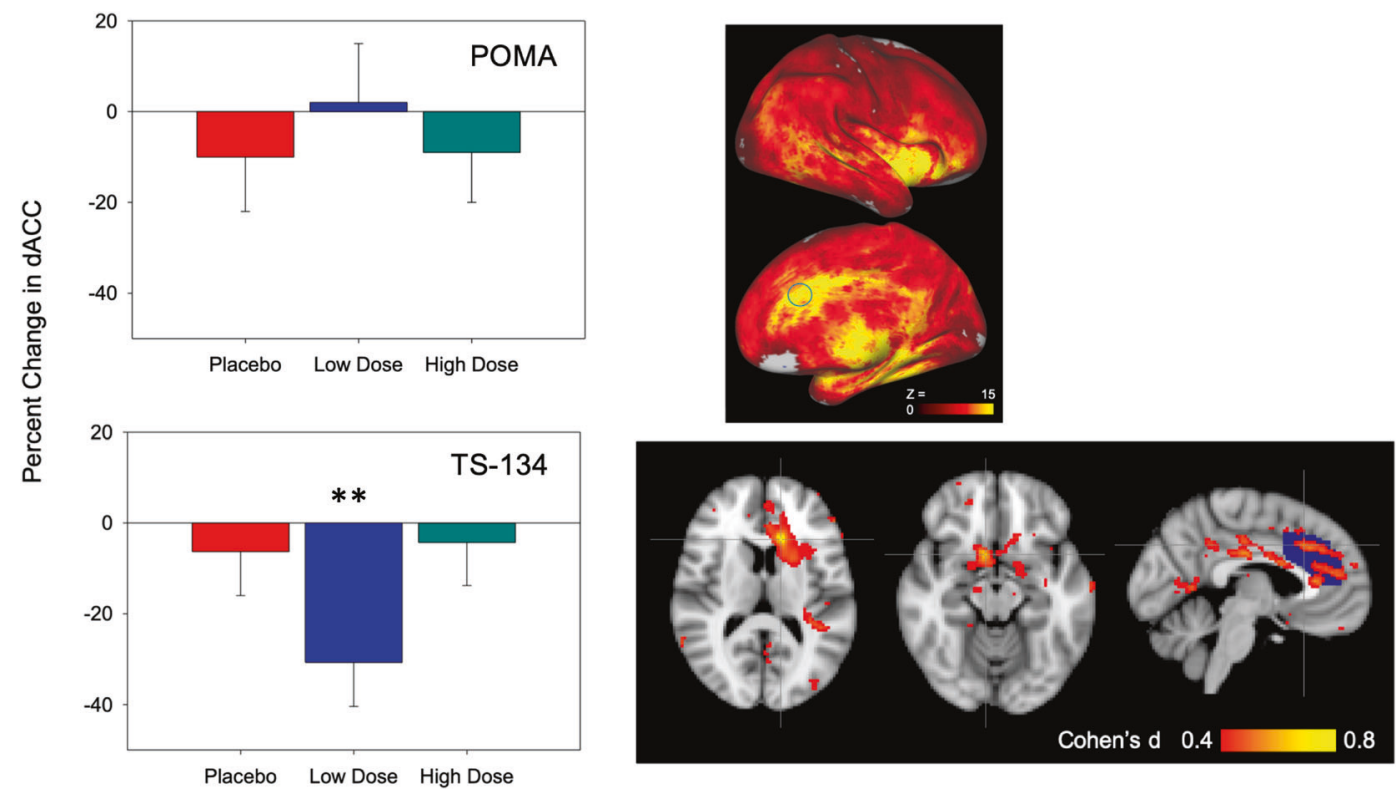

Fig. 3 PharmacoBOLD effects for the POMA and TS-134 study. Left: percent change in pharmacoBOLD response following ketamine administration on final assessments as compared to screening in the predefined region of interest (dorsal anterior cingulate cortex: $d A C C)$ for the POMA and TS-134 study. TS-134 results are for the combined Columbia University Medical Center/New York State Psychiatric Institute (CUMC/NYSPI) placebo sample. Model estimated mean \pm standard error. ${ }^{* *}=<0.01$ for within group changes. Right top: voxelwise activation maps. $z$ Statistic maps were thresholded at $z>0$. The circle indicates the region of interest used for primary analysis. Right bottom: TS-134 20-mg dose-related reduction in ketamine-evoked BOLD response. The difference in ketamine-evoked BOLD suppression was compared in low dose and the combined Columbia University Medical Center/New York State Psychiatric Institute (CUMC/NYSPI) placebo sample. The thresholded effect size map $(d=0.4-0.8)$ represents the contrast of (post-pre $)_{\text {low }}-(\text { post-pre })_{\text {placebo }}$ for 25 low dose and 23 placebo subjects. Overlay shows the dACC ROI (blue) we used for the primary outcome measure map. Significant voxels were $(p<0.05)$ present in the right ventral striatum and left caudate.

Additional pharmacoBOLD analyses

We examined treatment effects on additional ROI's that had been interrogated in a previous POMA study [31] and found a significant between-group difference in the supragenual paracingulate gyrus of moderate effect size for low-dose TS-134 ( $p=$ $0.02, d=-0.66$, Supplemental Fig. 3), but neither POMA dose nor high-dose TS-134 had significant effects on any other ROls. A significant within-group effect was observed for the prespecified secondary ROI (anterior insula) in the low-dose TS-134 group ( $t_{55}=3.5, p=0.001, d=-0.66$ ) but not for the high-dose group.

Finally, in the whole brain analysis, low-dose TS-134 significantly reduced pharmacoBOLD in the predefined $\mathrm{dACC}$ ROI, along with the left caudate and ventral striatum compared to the pooled placebo group (Fig. 3, bottom right, Supplemental Table 3). Whole brain analysis results were not significant after correction for multiple comparisons.

Confounding effects

We observed marked changes in heartrate and respiration, in response to ketamine in the course of the studies, so we continuously monitored these physiologic parameters on a subset of subjects across studies $(n=61)$ using a pulse oximeter and respiration belt. Consistent with a prior report [37], the time course of heart rate changes mirrored that of the pharmacoBOLD response to ketamine (Supplemental Fig. 4). Prompted by this, in a post hoc analysis, we examined POMA and TS-134 effects on dACC pharmacoBOLD response to ketamine controlling for heart rate and found that low-dose TS-134 exerted a moderate effect on dACC pharmacoBOLD within $(d=-0.41)$ and between-groups $(d=-0.47)$. Neither POMA nor TS-134 had any independent effects on heart rate or respiration.
Pharmacokinetics (Supplemental Table 4)

Ketamine levels were consistent with previous studies [13], similar between groups for both studies, and not correlated with pharmacoBOLD/symptom responses.

POMA and TS-134 drug levels were consistent with the dose/ plasma level pharmacokinetics determined in Phase 1 studies of both drugs and verified subject compliance with treatments.

\section{Safety}

Significant nausea/vomiting was seen during early dosing for both medications, necessitating a brief dose titration schedule for both drugs (Supplemental Figs. 5 and 6). Nausea/vomiting rates were greater with TS-134 than POMA. There were no serious or unexpected treatment emergent adverse events (TEAE: Table 2).

\section{DISCUSSION}

We believe that the results of these studies warrant continued development of mGluR2/3 agonists as potential treatments for schizophrenia. Both drugs ameliorated ketamine-induced symptoms specific to schizophrenia, though only the low dose of TS134 demonstrated target engagement reflected by attenuation of ketamine-induced pharmacoBOLD.

The findings of our studies indicate that the prior negative results from Lilly's phase III studies may have been due to inadequate doses used in pivotal studies (80 mg/day, [32-34]). Our study found that the most efficacious dose used in the phase III trials did not significantly inhibit attenuation of ketamine-induced pharmacoBOLD response, nor suppress symptoms. By contrast, POMA doses $\sim 4 \mathrm{x}$ higher $(320 \mathrm{mg} / \mathrm{day})$, did show significant suppression of ketamine-induced symptoms, supporting prior 


\begin{tabular}{|c|c|c|c|c|c|c|}
\hline Dose $(n)$ & $\begin{array}{l}20 \mathrm{mg}(27)(\%) \\
\text { TS-134 }\end{array}$ & $60 \mathrm{mg}(26)(\%)$ & Placebo (10) (\%) & $\begin{array}{l}80 \mathrm{mg}(24)(\%) \\
\text { Pomaglumetad }\end{array}$ & $320 \mathrm{mg}(29)(\%)$ & Placebo (28) (\%) \\
\hline Nausea & 14 (51.9) & $11(42.3)$ & $0(0)$ & $11(45.8)$ & $9(31.0)$ & $2(7.1)$ \\
\hline Dizziness & $3(11.1)$ & $6(23.1)$ & $0(0)$ & $1(4.2)$ & $7(24.1)$ & $1(3.6)$ \\
\hline Headache & $3(11.1)$ & $3(11.5)$ & $0(0)$ & $6(25.0)$ & $4(13.8)$ & $4(14.3)$ \\
\hline Diarrhea & $0(0)$ & $3(11.5)$ & $0(0)$ & $0(0)$ & $3(10.3)$ & $0(0)$ \\
\hline Pruritus/itchiness & $0(0)$ & $2(7.6)$ & $1(10)$ & $0(0)$ & $2(6.9)$ & $0(0)$ \\
\hline Diaphoresis & $1(3.7)$ & $1(3.8)$ & $0(0)$ & $1(4.2)$ & $2(6.9)$ & $0(0)$ \\
\hline Dry mouth & $0(0)$ & $1(3.8)$ & $0(0)$ & $1(4.2)$ & $0(0)$ & $3(10.7)$ \\
\hline
\end{tabular}

ndings of high-dose POMA [31] pharmacoBOLD fMRI attenuation. The fact that the high dose of POMA did ameliorate psychotic symptoms provoked by ketamine but did not exhibit target engagement as reflected in the pharmacoBOLD fMRI response suggests that even our high dose of POMA may still have been too low for optimal target engagement.

On the other hand, the more pharmacologically potent TS-134 achieved target engagement and symptom reduction at the low but not the high dose. Preclinical studies $[29,30]$ indicate that TS134 may be more potent than POMA. The side effect rates and severity of nausea and vomiting for TS-134 were also consistent with this impression. This pattern of results suggests that highdose POMA was on the lower part of the ascending limb of the dose-response curve and the TS-134 low dose was at the asymptote while the high dose was on the descending limb of a curvilinear dose-response curve.

While further clinical and preclinical work is required to confirm a curvilinear dose-response curve for mGluR2/3 agonists, support comes from both the literature and consulting with Dr. Darryl Schoepp (who developed a series of mGluR compounds, including POMA, as VP for Neuroscience Research at Lilly 1987-2007). As previously reviewed [38], mGluR3 activation may be neuroprotective via astrocyte induced neurotrophic factors, including transforming-growth factor- $\beta 1$ or glial cell-derived neurotrophic factor [39-41]. Receptor desensitization, particularly for mGluR3s, could occur at higher occupancy levels [42]. While the precise relative proportion of $m$ GluR2 and mGluR3 receptor affinities of POMA and TS-134 at the doses used is unknown, POMA may have relatively larger mGlu2 vs. mGlu3 activity [43]. Thus, even highdose POMA may not have reached the level to cause desensitization of mGlu3 activity. Further support for a curvilinear dose response for mGluR2/3 agonists comes from primate studies, in which low doses of mGluR2/3 agonists increased neuronal firing rates and improved performance on a working memory task, whereas higher doses had inconsistent effects, with possible worsening [44].

PharmacoBOLD $\mathrm{fMRI}$ provides an indirect functional measure of target engagement, as compared to PET ligands which bind directly to the molecular target. While ${ }^{1} \mathrm{H}$ MRS may be a more specific measure of target engagement and was validated as such in our prior study [13], pharmacoBOLD fMRI was selected for the current study due to its substantially larger effect size.

A potential limitation of BOLD fMRI as a biomarker is the potential for confounding cardio-respiratory effects. Physiologic responses to ketamine can influence cerebrovascular volume and oxygenation [37, 45-47], and thus pharmacoBOLD. However, preclinical studies show that the tachycardic effects of NMDAR antagonism are brain mediated [48-54], potentially via glutamate $[49,51-54]$. Furthermore, similar NMDAR antagonism-induced effects are observed in both anesthetized, ventilated [55-58], and freely moving animals $[26,43,59-61]$, and across multiple imaging modalities that are not affected by overall brain perfusion in humans, including ${ }^{13} \mathrm{C}$ MRS and PET FDG [62-64]. This argues that ketamine-induced cardiorespiratory effects are not driving the pharmacoBOLD signal, but may add "noise" to phBOLD comparisons, and confirms that the model can still be a sensitive measure of target engagement even without adjusting for nonspecific perfusion effects.

Our interpretation is consistent with a recent report [37] showing that ketamine produces a measurable pharmacoBOLD response after correcting for the physiologic response. Thus, we believe our results reflect mGluR2/3 agonist target engagement, as neither POMA nor TS-134 had any independent effects on heart rate or respiration. These results notwithstanding, further optimization of the approach seems warranted, including parametric variation in ketamine dose, increased physiological monitoring and statistical modeling of whole-brain BOLD effects [37]. In doing so, the remaining variance in BOLD activity unrelated to peripherally driven physiological effects reflects the neural contribution more reliably be taken to arise neuronally and reflect drug effects on glutamatergic, neural activity [45-47].

Because the TS-134 study was primarily designed to detect within-group effects to define optimal doses, an asymmetric randomization schedule was employed. In general, Cohen's $d \geq 0.5$ are considered "visible to the naked eye of the careful observer" [65] and are widely considered to be the threshold for meaningful clinical effect. Nonetheless, while TS-134 $20 \mathrm{mg}$ produced significant within-group improvements on ketamine-induced positive symptoms $(p=0.02)$ and pharmacoBOLD $(p=0.004)$, the within study between group effects for pharmacoBOLD, though of moderate effect size $(d=-0.57$, Supplemental Table 2$)$, were not significant. For this reason, we performed the analysis with the pooled-placebo group to achieve a larger sample size, which revealed a more robust between-group effect on symptoms $(p=0.008)$, and a trend-level of significance, moderate effect size, pharmacoBOLD change ( $p=0.079, d=-0.50)$.

Our predefined ROI ( $\mathrm{dACC}$ ) was chosen based on the peak response $\mathrm{ROI}$ in our prior work [13], and further supported by previous pharmacoBOLD studies $[25,31]$. Moreover, significant correlations are seen between dACC glutamate and antipsychotic treatment response $[66,67]$. These findings correspond as well with FDG-PET studies that found increased prefrontal metabolism 
in unmedicated Sz [68] and ${ }^{1} \mathrm{H}$ MRS studies showing elevated prefrontal glutamate [69]. Thus, our findings appear clinically relevant. Furthermore, the whole brain analysis showed drug effects primarily within the predefined dACC ROI, along with significant clusters within dopaminergic areas (ventral striatum and caudate), consistent with preclinical studies suggesting broad interactions between mGluR2/3 and dopaminergic neurotransmission [70-72]. We caution that the whole brain analysis was not corrected for multiple comparisons and requires prospective replication.

Interestingly, neither POMA nor TS-134 had effects on the CADSS ratings. This is revealing in that while the BPRS measures psychopathology, the CADSS largely measures more non-specific ketamine effects, such as disassociation, novelty and sensory disturbance. In this context, while ketamine stimulates both psychopathology and disassociation effects, mGluR2/3 agonists act on the former and not the latter, suggesting that its effects were specifically antipsychotic.

The originally proposed trial designs called for patients to start at the target dose of their treatment group. However, because of nausea/vomiting that occurred rapidly after first dose administration, a titration schedule was instituted so that target dose in the high groups was not achieved for several days (Supplemental Tables 5 and 6). The gradual titration reduced the frequency and severity of nausea substantially and no subjects discontinued due to nausea. Overall, $89.8 \%$ of the randomized sample completed the study.

Interestingly, nausea/vomiting was more severe with TS-134 (Table 2), supporting the increased potency of TS-134 relative to POMA. The rapid onset of nausea/vomiting suggests that the critical receptors may be either peripheral (in the gut) or in parts of the brain (e.g. brainstem/area postrema) that are not protected by the blood-brain barrier. If so, it suggests that pairing a centrally penetrant mGluR2/3 agonist with a non-penetrant antagonist may permit more rapid treatment implementation. Alternatively, a slow titration, as used here, may be required during clinical utilization.

In conclusion, our results demonstrate sufficient proof of principle and mechanism to support continued development of mGluR2/3 agonists as treatments for schizophrenia at empirically optimized doses. The fact that POMA failed in Lilly's pivotal trials at doses of $80 \mathrm{mg}$ [32-34] and to exhibit therapeutic benefits and target engagement at the same dose in our study [31], should not preclude glutamate mGluR2/3 targeted treatments as valid and viable. However, thorough determination of their therapeutic potential requires dose optimization and better characterization of the pharmacodynamics of glutamatergic neurotransmission at the relevant molecular targets.

\section{FUNDING AND DISCLOSURE}

The POMA study was supported by the FAST-PS contract (HHSN271201200007I) from NIMH. The TS-134 study was supported by Taisho Pharmaceutical R\&D Inc. Dr. Kantrowitz reports having received consulting payments within the last 24 months from Krog \& Partners Incorporated, IQVIA, Alphasights, Charles River Associates, Putnam Associates, Third Bridge, Piper Jaffray, MEDACorp, Simon Kucher, LifeSci Capital, ECRI Institute, L.E.K. and System Analytic. He has served on the Aristada Schizophrenia Advisory Board for Alkermes and the MedinCell Psychiatry Advisory Board. He has conducted clinical research supported by the NIMH, Sunovion, the Stanley Foundation, Takeda, Taisho, Lundbeck, Boehringer Ingelheim, NeuroRX, Teva and Lilly within the last 24 months. Dr. Kantrowitz a co-investigator on a study that receives lumeteperone and reimbursement for safety testing for an investigator-initiated research from Intra-Cellular Therapies Inc. He owns a small number of shares of common stock from GSK. Dr. Goff does not accept any personal financial remuneration for consulting, speaking or research activities from any pharmaceutical, biotechnology, or medical device companies. He has received funding for research from Avanir Pharmaceuticals which does not contribute to his compensation. He has served as a consultant or advisory board member for the Welcome Trust, Intra-Cellular Therapies, Takeda, and Avanir Pharmaceuticals for which he receives no personal remuneration. Dr. Marder has served on advisory boards for Sunovion, Roche, Boeringer Ingellheim, and Merck. He has received research support from Takeda and Boeringer Ingelheim. Dr. Girgis reports research support from BioAdvantex, Genentech, Otsuka and Allergan and receives royalties from Routledge/Taylor and Francis. Dr. Green has been a consultant for Biogen, Click Therapeutics, Lundbeck, and Roche, and he is on the Scientific Board of Cadent. Dr. Krystal reports having received consulting payments from AstraZeneca Pharmaceuticals, Biogen, Biomedisyn Corporation, Bionomics, Boehringer Ingelheim International, COMPASS Pathways, Concert Pharmaceuticals, Epiodyne, EpiVario, Heptares Therapeutics, Janssen Research \& Development, Otsuka America Pharmaceutical, Perception Neuroscience Holdings, Spring Care, Sunovion Pharmaceuticals, Takeda Industries, and Taisho Pharmaceutical. He has served on advisory boards for Bioasis Technologies, Biohaven Pharmaceuticals, BioXcel Therapeutics, BlackThorn Therapeutics, Cadent Therapeutics, Cerevel Therapeutics, EpiVario, Eisai, Lohocla Research Corporation, Novartis Pharmaceuticals Corporation, and PsychoGenics. He is a cosponsor of a patent for the intranasal administration of ketamine for the treatment of depression and for the treatment of suicide risk that was licensed by Janssen Pharmaceuticals; has a patent related to the use of riluzole to treat anxiety disorders that was licensed by Biohaven Pharmaceuticals; has stock or stock options in Biohaven Pharmaceuticals, Blackthorn Therapeutics, Luc Therapeutics, Cadent Pharmaceuticals, Terran Biosciences, Spring Healthcare, and Sage Pharmaceuticals. He serves on the Board of Directors of Inheris Pharmaceuticals. He receives compensation for serving as editor of the journal Biological Psychiatry. Dr. Javitt reports having received consulting payments from Pfizer, FORUM, Autifony, Glytech, Lundbeck, Concert, and Cadence. He holds intellectual property rights for use of NMDA modulators in treatment of neuropsychiatric disorders. He holds equity in Glytech, AASI, and NeuroRx, and serves on the advisory board of Promentis, Phytec and NeuroRx. Dr. Lieberman does not accept any personal financial remuneration for consulting, speaking or research activities from any pharmaceutical, biotechnology, or medical device companies. He receives funding and medication supplies for investigatorinitiated research from Denovo, Taisho, Pfizer, Sunovion, and Genentech, and for company sponsored phase II, III, and IV studies from Alkermes, Allergan, Boehringer Ingelheim, and Sunovion which does not contribute to his compensation. He receives medication supplies for investigator-initiated research from Intra-Cellular Therapies Inc. He is a consultant or advisory board member of Intra-Cellular Therapies, Takeda, Pierre Fabre, Karuna, Pear Therapeutics, Systems-1, and Psychogenics for which he receives no remuneration. He is a paid consultant for Bracket, a clinical research services organization, and holds a patent from Repligen that yields no royalties. The authors declare no competing interests.

\section{AUTHOR CONTRIBUTIONS}

JAL and JTK had full access to all of the data in the study and takes responsibility for the integrity of the data and the accuracy of the data analysis. All authors reviewed the final submission and gave final approval of the submitted version. Substantial contributions to conception and design: JTK, DCJ, JG, MMW, RRG, T-HC, LSK, JHK, WZP, and JAL. Acquisition, analysis, or interpretation of data: JTK, DCJ, RRG, LSK, MMW, TS, T-HC, JG, JAL, DCG, ACL, MFG, YSY, JL, and SRM. Drafting of the manuscript: JTK, DCJ, MMW, LSK, T-HC, JG, and JAL. Critical revision of the 
manuscript for important intellectual content: JTK, DCJ, GH, JHK, WZP, MMW, T-HC, JG, LSK, and JAL.

Publisher's note Springer Nature remains neutral with regard to jurisdictional claims in published maps and institutional affiliations.

\section{REFERENCES}

1. Kapur S, Remington $G$. Dopamine $D(2)$ receptors and their role in atypical antipsychotic action: still necessary and may even be sufficient. Biol Psychiatry. 2001;50:873-83.

2. Huhn $M$, Nikolakopoulou A, Schneider-Thoma J, Krause $M$, Samara $M$, Peter $N$ et al. Comparative efficacy and tolerability of 32 oral antipsychotics for the acute treatment of adults with multi-episode schizophrenia: a systematic review and network meta-analysis. Lancet. 2019;394:939-51.

3. Kahn RS, Fleischhacker WW, Boter $H$, Davidson $M$, Vergouwe $Y$, Keet IP, et al. Effectiveness of antipsychotic drugs in first-episode schizophrenia and schizophreniform disorder: an open randomised clinical trial. Lancet. 2008;371:1085-97.

4. Lieberman JA, Stroup TS, McEvoy JP, Swartz MS, Rosenheck RA, Perkins DO, et al. Effectiveness of antipsychotic drugs in patients with chronic schizophrenia. $\mathrm{N}$ Engl J Med. 2005;353:1209-23.

5. Kantrowitz JT. Managing negative symptoms of schizophrenia: how far have we come? CNS Drugs. 2017;31:373-88.

6. Girgis RR, Zoghbi AW, Javitt DC, Lieberman JA. The past and future of novel, nondopamine-2 receptor therapeutics for schizophrenia: A critical and comprehensive review. J Psychiatr Res. 2019;108:57-83.

7. Javitt DC, Zukin SR. Recent advances in the phencyclidine model of schizophrenia. Am J Psychiatry. 1991;148:1301-8.

8. Krystal JH, Karper LP, Seibyl JP, Freeman GK, Delaney R, Bremner JD, et al. Subanesthetic effects of the noncompetitive NMDA antagonist, ketamine, in humans. Psychotomimetic, perceptual, cognitive, and neuroendocrine responses. Arch Gen Psychiatry. 1994;51:199-214.

9. Kinon BJ, Gomez JC. Clinical development of pomaglumetad methionil: a nondopaminergic treatment for schizophrenia. Neuropharmacology. 2013;66:82-6.

10. Kantrowitz JT, Nolan KA, Epstein ML, Lehrfeld N, Shope C, Petkova E, et al. Neurophysiological effects of bitopertin in schizophrenia. J Clin Psychopharmacol. 2017;37:447-51.

11. Schoemaker JH, Jansen WT, Schipper J, Szegedi A. The selective glycine uptake inhibitor org 25935 as an adjunctive treatment to atypical antipsychotics in predominant persistent negative symptoms of schizophrenia: results from the GIANT trial. J Clin Psychopharmacol. 2014;34:190-8.

12. Suridjan I, Comley RA, Rabiner EA. The application of positron emission tomography (PET) imaging in CNS drug development. Brain Imaging Behav. 2019;13:354-65.

13. Javitt DC, Carter CS, Krystal JH, Kantrowitz JT, Girgis RR, Kegeles LS, et al. Utility of imaging-based biomarkers for glutamate-targeted drug development in psychotic disorders: a randomized clinical trial. JAMA Psychiatry. 2018:75:11-9.

14. Moghaddam B, Adams B, Verma A, Daly D. Activation of glutamatergic neurotransmission by ketamine: a novel step in the pathway from NMDA receptor blockade to dopaminergic and cognitive disruptions associated with the prefrontal cortex. J Neurosci. 1997;17:2921-7.

15. Chowdhury GM, Behar KL, Cho W, Thomas MA, Rothman DL, Sanacora G. (1)H-[(1) (3)C]-nuclear magnetic resonance spectroscopy measures of ketamine's effect on amino acid neurotransmitter metabolism. Biol Psychiatry. 2012;71:1022-5.

16. Grunze HC, Rainnie DG, Hasselmo ME, Barkai E, Hearn EF, McCarley RW, et al. NMDA-dependent modulation of CA1 local circuit inhibition. J Neurosci. 1996;16:2034-43.

17. Rothman DL, De Feyter HM, de Graaf RA, Mason GF, Behar KL. 13C MRS studies of neuroenergetics and neurotransmitter cycling in humans. NMR Biomed. 2011;24:943-57.

18. Vijayakumari AA, Thomas B, Menon RN, Kesavadas C. Association between glutamate/glutamine and blood oxygen level dependent signal in the left dorsolateral prefrontal region during verbal working memory. Neuroreport. 2018;29:478-82

19. Ip B, Berrington A, Hess AT, Parker AJ, Emir UE, Bridge H. Combined fMRI-MRS acquires simultaneous glutamate and BOLD-fMRI signals in the human brain. Neuroimage. 2017;155:113-9.

20. Enzi B, Duncan NW, Kaufmann J, Tempelmann C, Wiebking C, Northoff G. Glutamate modulates resting state activity in the perigenual anterior cingulate cortex - a combined fMRI-MRS study. Neuroscience. 2012;227:102-9.

21. Cleve M, Gussew A, Wagner G, Bar KJ, Reichenbach JR. Assessment of intra- and inter-regional interrelations between GABA+, Glx and BOLD during pain perception in the human brain - a combined (1)H FMRS and fMRI study. Neuroscience. 2017;365:125-36.
22. Gozzi A, Large CH, Schwarz A, Bertani S, Crestan V, Bifone A. Differential effects of antipsychotic and glutamatergic agents on the phMRI response to phencyclidine. Neuropsychopharmacology. 2008;33:1690-703.

23. Schobel SA, Chaudhury NH, Khan UA, Paniagua B, Styner MA, Asllani I, et al Imaging patients with psychosis and a mouse model establishes a spreading pattern of hippocampal dysfunction and implicates glutamate as a driver. Neuron. 2013;78:81-93.

24. Lieberman JA, Girgis RR, Brucato $G$, Moore $H$, Provenzano F, Kegeles $L$, et al. Hippocampal dysfunction in the pathophysiology of schizophrenia: a selective review and hypothesis for early detection and intervention. Mol Psychiatry. 2018;23:1764-72

25. De Simoni S, Schwarz AJ, O'Daly OG, Marquand AF, Brittain C, Gonzales C, et al. Test-retest reliability of the BOLD pharmacological MRI response to ketamine in healthy volunteers. Neuroimage. 2013;64:75-90.

26. Moghaddam B, Adams BW. Reversal of phencyclidine effects by a group II metabotropic glutamate receptor agonist in rats. Science. 1998;281:1349-52.

27. Lorrain DS, Baccei CS, Bristow LJ, Anderson JJ, Varney MA. Effects of ketamine and $\mathrm{N}$-methyl-D-aspartate on glutamate and dopamine release in the rat prefrontal cortex: modulation by a group II selective metabotropic glutamate receptor agonist LY379268. Neuroscience. 2003;117:697-706.

28. Chin CL, Upadhyay J, Marek GJ, Baker SJ, Zhang M, Mezler M, et al. Awake rat pharmacological magnetic resonance imaging as a translational pharmacodynamic biomarker: metabotropic glutamate $2 / 3$ agonist modulation of ketamineinduced blood oxygenation level dependence signals. J Pharm Exp Ther 2011;336:709-15.

29. Rorick-Kehn LM, Johnson BG, Knitowski KM, Salhoff CR, Witkin JM, Perry KW, et al. In vivo pharmacological characterization of the structurally novel, potent, selective mGlu2/3 receptor agonist LY404039 in animal models of psychiatric disorders. Psychopharmacology. 2007;193:121-36.

30. Takamori K, Hirota S, Chaki S, Tanaka M. Antipsychotic action of selective group I metabotropic glutamate receptor agonist MGS0008 and MGS0028 on conditioned avoidance responses in the rat. Life Sci. 2003;73:1721-8.

31. Mehta MA, Schmechtig A, Kotoula V, McColm J, Jackson K, Brittain C, et al. Group II metabotropic glutamate receptor agonist prodrugs LY2979165 and LY2140023 attenuate the functional imaging response to ketamine in healthy subjects. Psychopharmacology. 2018;235:1875-86.

32. Adams DH, Zhang L, Millen BA, Kinon BJ, Gomez JC. Pomaglumetad methionil (LY2140023 monohydrate) and aripiprazole in patients with schizophrenia: a phase 3, multicenter, double-blind comparison. Schizophrenia Res Treat. 2014;2014:758212.

33. Kinon BJ, Millen BA, Zhang L, McKinzie DL. Exploratory analysis for a targeted patient population responsive to the metabotropic glutamate $2 / 3$ receptor agonist pomaglumetad methionil in schizophrenia. Biol Psychiatry. 2015;78:754-62.

34. Kinon BJ, Zhang L, Millen BA, Osuntokun OO, Williams JE, Kollack-Walker S, et al. A multicenter, inpatient, phase 2, double-blind, placebo-controlled dose-ranging study of LY2140023 monohydrate in patients with DSM-IV schizophrenia. J Clin Psychopharmacol. 2011;31:349-55.

35. American Psychiatric Association. Diagnostic and statistical manual of mental disorders: DSM-5. 5th ed. Arlington, VA: American Psychiatric Association. 2013.

36. Overall JE, Gorham DE. The brief psychiatric rating scale. Psychol Rep. 1962;10:799-812.

37. McMillan R, Forsyth A, Campbell D, Malpas G, Maxwell E, Dukart J, et al. Temporal dynamics of the pharmacological MRI response to subanaesthetic ketamine in healthy volunteers: A simultaneous EEG/fMRI study. J Psychopharmacol. 2019;33:219-29.

38. Nicoletti F, Orlando R, Di Menna L, Cannella M, Notartomaso S, Mascio G, et al Targeting mGlu receptors for optimization of antipsychotic activity and diseasemodifying effect in schizophrenia. Front Psychiatry. 2019;10:49.

39. Bruno V, Battaglia G, Casabona G, Copani A, Caciagli F, Nicoletti F. Neuroprotection by glial metabotropic glutamate receptors is mediated by transforming growth factor-beta. J Neurosci. 1998;18:9594-600.

40. Taylor DL, Jones F, Kubota ES, Pocock JM. Stimulation of microglial metabotropic glutamate receptor mGlu2 triggers tumor necrosis factor alpha-induced neurotoxicity in concert with microglial-derived Fas ligand. J Neurosci. 2005;25:2952-64.

41. Caraci F, Molinaro G, Battaglia G, Giuffrida ML, Riozzi B, Traficante A, et al. II metabotropic glutamate $(\mathrm{mGlu})$ receptors for the treatment of psychosis associated with Alzheimer's disease: selective activation of mGlu2 receptors amplifies beta-amyloid toxicity in cultured neurons, whereas dual activation of mGlu2 and mGlu3 receptors is neuroprotective. Mol Pharmacol. 2011;79:618-26.

42. Iacovelli L, Molinaro G, Battaglia G, Motolese M, Di Menna L, Alfiero M, et al. Regulation of group II metabotropic glutamate receptors by $\mathrm{G}$ protein-coupled 
receptor kinases: mGlu2 receptors are resistant to homologous desensitization. Mol Pharmacol. 2009;75:991-1003.

43. Fell MJ, Svensson KA, Johnson BG, Schoepp DD. Evidence for the role of metabotropic glutamate $(\mathrm{mGlu}) 2$ not $\mathrm{mGlu} 3$ receptors in the preclinical antipsychotic pharmacology of the mGlu2/3 receptor agonist (-)-(1 R,4 S,5 S,6 S)-4-amino-2sulfonylbicyclo[3.1.0] hexane-4,6-dicarboxylic acid (LY404039). J Pharm Exp Ther. 2008;326:209-17.

44. Jin LE, Wang M, Yang ST, Yang Y, Galvin VC, Lightbourne TC, et al. mGluR2/3 mechanisms in primate dorsolateral prefrontal cortex: evidence for both presynaptic and postsynaptic actions. Mol Psychiatry. 2017;22:1615-25.

45. Khalili-Mahani N, Chang C, van Osch MJ, Veer IM, van Buchem MA, Dahan A, et al. The impact of "physiological correction" on functional connectivity analysis of pharmacological resting state fMRI. Neuroimage. 2013;65:499-510.

46. Chang C, Cunningham JP, Glover GH. Influence of heart rate on the BOLD signal: the cardiac response function. Neuroimage. 2009;44:857-69.

47. Liebe T, Li S, Lord A, Colic L, Krause AL, Batra A, et al. Factors influencing the cardiovascular response to subanesthetic ketamine: a randomized, placebocontrolled trial. Int J Neuropsychopharmacol. 2017;20:909-18.

48. Jin YH, Bailey TW, Doyle MW, Li BY, Chang KS, Schild JH, et al. Ketamine differentially blocks sensory afferent synaptic transmission in medial nucleus tractus solitarius (mNTS). Anesthesiology. 2003;98:121-32.

49. Hoka S, Takeshita A, Sasaki T, Yoshitake J. Preservation of baroreflex control of vascular resistance under ketamine anesthesia in rats. J Anesthesia. 1988;2:207-12

50. Slogoff S, Allen GW. The role of baroreceptors in the cardiovascular response to ketamine. Anesth Analg. 1974;53:704-7.

51. Ogawa A, Uemura M, Kataoka Y, OI K, Inokuchi T. Effects of ketamine on cardiovascular responses mediated by $\mathrm{N}$-methyl-D-aspartate receptor in the rat nucleus tractus solitarius. Anesthesiology. 1993;78:163-7.

52. Camargo LH, Alves FH, Biojone C, Correa FM, Resstel LB, Crestani CC. Involvement of $\mathrm{N}$-methyl-D-aspartate glutamate receptor and nitric oxide in cardiovascular responses to dynamic exercise in rats. Eur J Pharm. 2013;713:16-24.

53. Ferreira-Junior NC, Lagatta DC, Resstel LBM. Glutamatergic, GABAergic, and endocannabinoid neurotransmissions within the dorsal hippocampus modulate the cardiac baroreflex function in rats. Pflug Arch. 2018;470:395-411.

54. Gillies MJ, Huang Y, Hyam JA, Aziz TZ, Green AL. Direct neurophysiological evidence for a role of the human anterior cingulate cortex in central command. Auton. Neurosci. https://doi.org/10.1016/j.autneu.2018.09.004. 2018.

55. Gozzi A, Herdon H, Schwarz A, Bertani S, Crestan V, Turrini G, et al. Pharmacological stimulation of NMDA receptors via co-agonist site suppresses $\mathrm{fMRI}$ response to phencyclidine in the rat. Psychopharmacology. 2008;201:273-84.

56. Hackler EA, Byun NE, Jones CK, Williams JM, Baheza R, Sengupta S, et al. Selective potentiation of the metabotropic glutamate receptor subtype 2 blocks phencyclidine-induced hyperlocomotion and brain activation. Neuroscience. 2010;168:209-18.

57. Gass N, Schwarz AJ, Sartorius A, Schenker E, Risterucci C, Spedding M, et al. Subanesthetic ketamine modulates intrinsic BOLD connectivity within the hippocampal-prefrontal circuit in the rat. Neuropsychopharmacology. 2014;39:895-906.

58. Littlewood $\mathrm{CL}$, Jones N, O'Neill MJ, Mitchell SN, Tricklebank M, Williams SC. Mapping the central effects of ketamine in the rat using pharmacological MRI. Psychopharmacology. 2006;186:64-81.

59. Linn GS, O'Keeffe RT, Lifshitz K, Schroeder C, Javitt DC. Behavioral effects of orally administered glycine in socially housed monkeys chronically treated with phencyclidine. Psychopharmacology. 2007;192:27-38.

60. Baker S, Chin CL, Basso AM, Fox GB, Marek GJ, Day M. Xanomeline modulation of the blood oxygenation level-dependent signal in awake rats: development of pharmacological magnetic resonance imaging as a translatable pharmacody- namic biomarker for central activity and dose selection. J Pharm Exp Ther. 2012;341:263-73.

61. Li J, Ishiwari K, Conway MW, Francois J, Huxter J, Lowry JP, et al. Dissociable effects of antipsychotics on ketamine-induced changes in regional oxygenation and inter-regional coherence of low frequency oxygen fluctuations in the rat. Neuropsychopharmacology. 2014;39:1635-44.

62. Langsjo JW, Kaisti KK, Aalto S, Hinkka S, Aantaa R, Oikonen V, et al. Effects of subanesthetic doses of ketamine on regional cerebral blood flow, oxygen consumption, and blood volume in humans. Anesthesiology. 2003;99:614-23.

63. Langsjo JW, Maksimow A, Salmi E, Kaisti K, Aalto S, Oikonen V, et al. S-ketamine anesthesia increases cerebral blood flow in excess of the metabolic needs in humans. Anesthesiology. 2005;103:258-68.

64. Langsjo JW, Salmi E, Kaisti KK, Aalto S, Hinkka S, Aantaa R, et al. Effects of subanesthetic ketamine on regional cerebral glucose metabolism in humans. Anesthesiology. 2004;100:1065-71.

65. Cohen J. Statistical Power Analysis for the Behavioral Sciences. 2nd edn. Lawrence Erlbaum Assoc.: Hillsdale, NJ; 1988.

66. Egerton A, Broberg BV, Van Haren N, Merritt K, Barker GJ, Lythgoe DJ, et al. Response to initial antipsychotic treatment in first episode psychosis is related to anterior cingulate glutamate levels: a multicentre (1)H-MRS study (OPTiMiSE). Mol Psychiatry. 2018;23:2145-55.

67. Mouchlianitis E, Bloomfield MA, Law V, Beck K, Selvaraj S, Rasquinha N, et al. Treatment-resistant schizophrenia patients show elevated anterior cingulate cortex glutamate compared to treatment-responsive. Schizophr Bull. 2016;42:744-52.

68. Soyka M, Koch W, Moller HJ, Ruther T, Tatsch K. Hypermetabolic pattern in frontal cortex and other brain regions in unmedicated schizophrenia patients. Results from a FDG-PET study. Eur Arch Psychiatry Clin Neurosci. 2005;255:308-12.

69. Poels EM, Kegeles LS, Kantrowitz JT, Javitt DC, Lieberman JA, Abi-Dargham A, et al. Glutamatergic abnormalities in schizophrenia: a review of proton MRS findings. Schizophr Res. 2014;152:325-32.

70. Lane TA, Boerner T, Bannerman DM, Kew JN, Tunbridge EM, Sharp T, et al. Decreased striatal dopamine in group II metabotropic glutamate receptor (mGlu2/mGlu3) double knockout mice. BMC Neurosci. 2013;14:102.

71. Cartmell J, Perry KW, Salhoff CR, Monn JA, Schoepp DD. The potent, selective mGlu2/3 receptor agonist LY379268 increases extracellular levels of dopamine, 3,4-dihydroxyphenylacetic acid, homovanillic acid, and 5-hydroxyindole-3-acetic acid in the medial prefrontal cortex of the freely moving rat. J Neurochem. 2000;75:1147-54.

72. Greenslade RG, Mitchell SN. Selective action of (-)-2-oxa-4-aminobicyclo[3.1.0] hexane-4,6-dicarboxylate (LY379268), a group II metabotropic glutamate receptor agonist, on basal and phencyclidine-induced dopamine release in the nucleus accumbens shell. Neuropharmacology 2004;47:1-8.

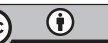

Open Access This article is licensed under a Creative Commons Attribution 4.0 International License, which permits use, sharing, adaptation, distribution and reproduction in any medium or format, as long as you give appropriate credit to the original author(s) and the source, provide a link to the Creative Commons license, and indicate if changes were made. The images or other third party material in this article are included in the article's Creative Commons license, unless indicated otherwise in a credit line to the material. If material is not included in the article's Creative Commons license and your intended use is not permitted by statutory regulation or exceeds the permitted use, you will need to obtain permission directly from the copyright holder. To view a copy of this license, visit http://creativecommons. org/licenses/by/4.0/.

(c) The Author(s) 2020 